\title{
IGUALDADE DE GÊNERO NAS ELEIÇÕES: A FRAUDE NO PROCESSO ELEITORAL ATRAVÉS DE CANDIDATAS LARANJAS
}

\author{
Gender equality in elections: the electoral frand through female stooge candidates
}

\author{
Camila Teixeira do Nascimento \\ Diogo Rais Rodrigues Moreira
}

Resumo: O uso de candidaturas laranja ganhou destaque nos últimos anos, apesar de ser uma prática supostamente antiga. $\mathrm{O}$ ato de fraudar as eleições com candidatas fictícias apenas para preencher a cota de gênero instituída em 1997 era uma prática reiterada dos partidos políticos. O presente trabalho busca compreender os esforços normativos para buscar a igualdade de gênero na política e quais foram as formas que os partidos políticos e coligações encontraram para dissimular as eleições proporcionais no país. Investiga também quais foram os entraves judiciais que barravam o julgamento dos atos ilícitos pela Justiça Eleitoral e quais as soluções trazidas para o caso concreto. Ao final, busca entender qual a atual situação em relação à punição dos partidos que cometem as fraudes e quais são os próximos passos para que a prática seja, ao menos condenada em última instância e pacificada na jurisprudência eleitoral brasileira.

Palavras-chave: Igualdade de gênero. Representatividade política. Fraude no processo eleitoral. Candidaturas fictícias.

\begin{abstract}
Female stooge candidature usage have been on the spotlight on recent years besides being a supposedly old practice. The act of fraud elections with fictitious candidatures only to meet the gender quota instituted in 1997 was a reiterated practice by political parties. The present study's purpose is to comprehend the normative efforts used to reach gender equality in politics. In addition, what ways political parties and coalitions found to disguise proportional elections at the country. It also investigates what legal impediments were blocking the trials of illegal acts by the Electoral Court and which were the solutions brought to real cases. In the end, it aims to understand what is the current situation regards punishment to parties that committed frauds and what are the next steps so that the practice become, at least, sentenced at last level and pacified on Brazilian electoral case law.
\end{abstract}

Keywords: Gender equality. Political representability. Electoral frauds. Fictitious candidatures.

\footnotetext{
${ }^{1}$ Pesquisa extraída do Trabalho de Conclusão de Curso, desenvolvido e defendido na Universidade Presbiteriana Mackenzie em junho/2019 sob a orientação do Professor Doutor Diogo Rais Rodrigues Moreira.
}

Artigo recebido em 22 jul. 2019 e aprovado em 19 ago. 2019. 


\section{Introdução}

A trajetória da mulher brasileira na política é, ao mesmo tempo, antiga e recente. A luta pelo ingresso e pela permanência nessa esfera de poder é um trabalho árduo e diário. Uma das pioneiras nesse assunto é Bertha Lutz, líder na luta pelos direitos políticos das mulheres ${ }^{2}$.

Bertha Lutz lutou pelo direito ao sufrágio feminino no Brasil desde 1919, quando criou a Liga para a Emancipação Intelectual da Mulher - que deu origem à Federação Brasileira pelo Progresso Feminino. Sua luta gerou frutos apenas 13 anos depois, quando foi alcançado o direito ao voto feminino, com o Decreto n⿳o 21.076, de 24 de fevereiro de $1932^{3}$, do então Presidente Getúlio Vargas, que instituiu o Código Eleitoral à época.

Antes desse acontecimento, porém, a professora Celina Guimarães Vianna se tornou a primeira eleitora não apenas do Brasil, como da América Latina, através da Lei $n^{\circ}$ 660, de 25 de outubro de 1927. Celina alistou-se na cidade de Mossoró, em Rio Grande do Norte, após o estado se tornar o primeiro a estabelecer que não haveria distinção de sexo para o exercício ao voto ${ }^{4}$.

No ano seguinte, Luíza Alzira Teixeira Soriano foi a primeira mulher eleita no Brasil. Tornou-se prefeita da cidade de Lages, no Rio Grande do Norte, com 60\% dos votos no pleito, fato este que teve repercussão mundial com o artigo do jornal estadunidense The New York Times, que mencionava que Alzira havia se tornado a primeira mulher a ser eleita para um cargo executivo em toda América Latina5.

\footnotetext{
${ }^{2}$ BERTHA Lutz. Senado Notícias, Brasília, DF, 2015. Disponível em: < https://www12. senado.leg.br/noticias/entenda-o-assunto/bertha-lutz> Acesso em: 9 maio 2019.

${ }^{3}$ BRASIL. Decreto $\mathbf{n}^{\mathbf{o}}$ 21.076, de 24 de fevereiro de 1932. Decreta o Código Eleitoral. Disponível em: <https://www2.camara.leg.br/legin/fed/decret/1930-1939/decreto-21076-24-fevereiro-1932-507583-publicacaooriginal-1-pe.html> . Acesso em: 1 maio 2019.

${ }^{4}$ PROFESSORA Celina Guimarães Vianna, primeira eleitora do Brasil. Tribunal Superior Eleitoral, Brasília, DF, s.d. Disponível em: < http://www.tse.jus.br/imagens/ fotos/professora-celina-guimaraes-vianna-primeira-eleitora-do-brasil> Acesso em: 9 maio 2019.

${ }^{5}$ BRASIL. Câmara dos Deputados. Diploma Mulher-Cidadã Carlota Pereira de Queirós. Comissão de Defesa dos Direitos da Mulher. Brasília, DF, 2018. Disponível em: <https://www2.camara.leg.br/atividade-legislativa/comissoes/comissoes-permanentes/ comissao-de-defesa-dos-direitos-da-mulher-cmulher/seminarios-e-outros-eventos/diploma-mulher-cidada-carlota-pereira-de-queiros/edicao-2018-diploma-mulher-cidada-carlota-pereira-de-queiros/resumo-alzira-soriano> Acesso em: 9 maio 2019.
} 
O que Bertha, Celina e Alzira têm em comum é a luta pelo ingresso, permanência e ativismo da mulher na política brasileira. Elas, como tantas outras, lutaram e lutam pela igualdade de gênero em um dos maiores tipos de poder do país: o poder de governar a população, o poder de debater quais as melhores formas de ajudar a sociedade.

Um século depois, o Brasil ainda enfrenta problemas com a igualdade de gênero nas eleições e na política. Apesar das políticas afirmativas instituídas sobre o tema, o eleitorado feminino ainda sofre com a baixa representatividade.

Em 1995, na IV Conferência Mundial sobre as Mulheres, em Pequim, foi instituído que os países signatários deveriam instituir políticas para ter mais representatividade da mulher nas esferas de poder: "O fortalecimento das mulheres e sua plena participação, em condições de igualdade, em todas as esferas sociais, incluindo a participação nos processos de decisão e acesso ao poder, são fundamentais para o alcance da igualdade, desenvolvimento e paz" .

Para tanto, no Brasil, foi criada, em 1997, a cota de gênero nas eleições, que determina que, no mínimo, $30 \%$ das candidaturas por partidos e/ ou coligações devem ser reservadas para um dos sexos. Porém, mesmo com essa política afirmativa, hoje em dia a representatividade feminina ainda é muito baixa.

De acordo com o Tribunal Superior Eleitoral, em 2016, o eleitorado brasileiro era formado por $47,7 \%$ de homens e $52,2 \%$ de mulheres. Nas eleições municipais daquele ano, 68,1\% das candidaturas apresentadas eram masculinas, contra 31,9\% de candidaturas femininas. Apesar de cumprir com a cota de gênero, apenas $13,4 \%$ dos eleitos eram mulheres, ou seja, houve apenas 7.512 mulheres assumindo cargos políticos nos municípios brasileiros, contra 48.458 homens $^{7}$.

\footnotetext{
${ }^{6}$ BRASIL. Câmara dos Deputados. Comissão de Direitos Humanos e Minorias. Declaração de Pequim Adotada pela Quarta Conferência Mundial sobre as Mulheres: Ação para Igualdade, Desenvolvimento e Paz. IV Conferência Mundial Sobre as Mulheres, Pequim, 15 set. 1995. Disponível em: <https://www2.camara.leg.br/atividade-legislativa/ comissoes/comissoes-permanentes/cdhm/comite-brasileiro-de-direitos-humanos-e-politica-externa/DecPequimquartconfmulh.html>. Acesso em: 7 maio 2019.

${ }^{7}$ ESTATÍSTICAS Eleitorais. 2016 e 2018 - Candidatura e Eleitorado. Tribunal Superior Eleitoral, Brasília, DF, s.d. Disponível em: < http://www.tse.jus.br/eleicoes/estatisticas/ estatisticas-eleitorais $>$ Acesso em: 8 maio 2019.
} 
Já em 2018, ano das eleições gerais, depois de ser instituído que a Reserva do Fundo Partidário e a propaganda eleitoral gratuita nos rádios e TVs também deveriam obedecer à cota de gênero da Lei das Eleições, o cenário pouco mudou. O eleitorado brasileiro era composto por 52,5\% de mulheres e 47,5\% de homens. Dentre as candidaturas, 19.881 (68,4\%) eram masculinas e $9.204(31,6 \%)$ eram femininas. Porém, entre os eleitos, encontravam-se $83,7 \%$ homens e apenas $16,3 \%$ mulheres, ou seja, dentre os 1.760 eleitos, apenas 287 eram mulheres ${ }^{8}$.

A dominância masculina no mundo político é alarmante. Mesmo com os esforços das instituições de aumentar a representatividade feminina na política, que representa a maior parte do eleitorado brasileiro, não aparenta surtir efeitos.

Os partidos políticos e as coligações elaboraram maneiras de fraudar o processo eleitoral desenvolvendo as chamadas "candidaturas laranjas", que são candidaturas fictícias femininas criadas somente para cumprir a cota de gênero, ou seja, registram candidatas que não apresentam gastos com campanhas e nem se empenham para ganhar a eleição, apenas para que os candidatos do sexo masculino tenham o direito de participar.

O presente trabalho busca entender a legislação eleitoral no que tange a igualdade de gênero e os motivos para que a fraude ao processo eleitoral tenha ganhado destaque uma década depois de ter sido instituída a cota de gênero nas eleições. Busca compreender quais foram os entraves jurídicos para discussão do tema e qual a atual situação em que se encontra.

\section{A legislação eleitoral e a igualdade de gênero}

A mulher brasileira conquistou o direito ao voto apenas em 1932, através do Decreto no 21.076, de 24 de fevereiro de 1932, que instituiu o então Código Eleitoral na época. Essa conquista veio depois de muitas lutas e discussões sobre o tema em todo o país. Porém, apenas o direito ao sufrágio não foi e não é o suficiente para alcançar a tão desejada igualdade de gênero, tanto na esfera social como na política.

\footnotetext{
${ }^{8}$ ESTATÍSTICAS Eleitorais. 2016 e 2018 - Candidatura e Eleitorado. Tribunal Superior Eleitoral, Brasília, DF, s.d. Disponível em: <http://www.tse.jus.br/eleicoes/estatisticas/ estatisticas-eleitorais $>$ Acesso em: 8 maio 2019.
} 
Foram instituídas, ao longo dos anos, diversas ações afirmativas, como tentativa de alcançar a igualdade de gênero. De acordo com o Guia Prático: a participação da mulher brasileira na política:

A instituição de medidas, no Direito brasileiro, de fomento à participação política da mulher se deu em um contexto muito mais amplo de discussão sobre a desigualdade entre os sexos nos espaços formais de poder, principalmente após a realização da IV Conferência Mundial sobre a Mulher de 1995, em Beijing, na China9.

A ação afirmativa que será tratada neste trabalho é a cota de gênero na política, instituída pela Lei das Eleições.

\subsection{Cotas de gênero}

A IV Conferência Mundial sobre a Mulher de 1995, em Beijing, na China, trouxe para o Brasil a primeira incidência das cotas de gênero nas eleições, pois a Lei no 9.100 de 29 de setembro de $1995^{10}$, que estabeleceu as normas para as eleições municipais de 1996, instituiu que, no mínimo, $20 \%$ das vagas de cada partido ou coligação deveriam ser preenchidas por candidatas mulheres.

Após, a Lei das Eleições ${ }^{11}$ (Lei nº 9.504 de 30 de setembro de 1997) estabeleceu, em seu art. 10, \3ㅜㅇ que cada partido ou coligação deveria reservar a cota mínima de $30 \%$, e máxima de $70 \%$, para candidaturas de cada sexo.

Com a minirreforma eleitoral de $2009^{12}$ (Lei no 12.034 de 30 de setembro de 2009), foi estabelecido que os partidos ou coligação deveriam efetivamente preencher a reserva de cotas de cada gênero, tornando, dessa forma, obrigatória a presença de mulheres nas eleições proporcionais.

\footnotetext{
${ }^{9}$ MACHADO, Raquel Cavalcanti Ramos. Guia prático: A participação da mulher brasileira na política. Fortaleza: Observatório Eleitoral do Ceará, 2019.

${ }^{10}$ BRASIL. Lei $\mathbf{n}^{\mathbf{0}} \mathbf{9 . 1 0 0}$, de 29 de setembro de 1995. Estabelece normas para a realização das eleições municipais de 3 de outubro de 1996, e dá outras providências. Disponível em: <http://www.planalto.gov.br/ccivil_03/leis/L9100.htm>. Acesso em: 8 maio 2019.

${ }^{11}$ Id. Lei no 9.504, de 30 de setembro de 1997. Estabelece normas para as eleições. Disponível em: <http://www.planalto.gov.br/ccivil_03/leis/19504.htm>. Acesso em: 8 maio 2019.

${ }^{12}$ Id. Lei $\mathbf{n}^{\mathbf{0}} \mathbf{1 2 . 0 3 4}$, de 30 de setembro de 2009. Altera as Leis $\mathrm{n}^{-}$9.096, de 19 de setembro de 1995 - Lei dos Partidos Políticos, 9.504, de 30 de setembro de 1997, que estabelece normas para as eleições, e 4.737, de 15 de julho de 1965 - Código Eleitoral. Disponível em: <http://www.planalto.gov.br/ccivil_03/_Ato2007-2010/2009/Lei/L12034.htm>. Acesso em: 8 maio 2019.
} 


\subsection{Candidatas laranjas}

Para melhor esclarecer, cabe traçar aqui a definição de "candidatas laranjas" e qual a sua função no processo eleitoral.

O termo "laranja", na linguagem popular, refere-se a alguém que comete fraude para benefício de outrem, conforme define Juvêncio (2013, p. 4):

[...] "laranja" pode ser alguém que com consentimento prévio assume uma identidade de maneira indevida e enganosa. Mesmo sem o consentimento prévio, ainda assim o termo "laranja" é utilizado de uma maneira que o/a "laranja" assume de forma enganosa uma identidade social ${ }^{13}$.

Para fins eleitorais, o termo "candidata laranja" é utilizado para definir as candidaturas femininas usadas para preencher a cota de gênero instituída pela Lei das Eleições e, para que os recursos da reserva de fundo partidário sejam repassados para outros candidatos do partido e/ou coligação.

Essas pessoas podem ter, ou não, conhecimento de suas candidaturas. O primeiro caso, mesmo tendo pleno conhecimento da lei e da possível fraude que cometeu, realiza a candidatura a título gratuito ou oneroso para benefício de outrem. O segundo caso, as candidaturas são lançadas ilegalmente, sem o consentimento prévio da pessoa afetada, pelo partido e / ou coligação.

Ainda que incertas, existem formas de identificação dessas candidaturas laranjas:

Candidatas que não estão fazendo campanha, que não recebem nenhum ou pouquíssimos votos, que não têm movimentação financeira, que recebem recursos do Fundo Partidário ou Fundo Especial de Campanha, mas que não os aplicam em prol da sua campanha, para viabilizá-la, podem ser um indicativo de que essas são "laranjas"14.

${ }^{13}$ JUVÊNCIO, José Sérgio Martins. A relação entre candidaturas "laranjas" e a lei de cotas por gênero. In: Encontro Internacional Participação, Democracia e Políticas Públicas: aproximando agendas e agentes, 1.2013, Araraquara. Encontro Araraquara: UNESP, 2013, p. 4.

${ }^{14}$ MACHADO, Raquel Cavalcanti Ramos. Guia prático: A participação da mulher brasileira na política. Fortaleza: Observatório Eleitoral do Ceará, 2019. 
Com a identificação das possíveis candidaturas laranjas, há medidas que devem ser tomadas para investigar, discutir e julgar cada caso: denúncia da situação para o Ministério Público Eleitoral, propositura de Ação de Investigação Judicial Eleitoral (AIJE) ou Ação de Impugnação de Mandato Eletivo (AIME) perante a Justiça Eleitoral contra os partidos e/ ou coligação e os candidatos que estão registrados no Demonstrativo de Regularidade de Atos Partidários (DRAP).

\section{Os obstáculos processuais}

Desde que a cota de gênero foi criada no Brasil, na Lei no 9.504/97 (Lei Geral das Eleições), os partidos e as coligações criaram formas para fraudá-la. Diante deste cenário, as candidatas laranjas, como discutido anteriormente, apareceram no cenário político e eleitoral brasileiro. Mas, mesmo sendo uma ação antiga, de certa forma, os casos de fraude à lei só passaram a ser discutidos abertamente na esfera judicial há pouco tempo. Isto se deve ao fato de que não havia ações judiciais cabíveis para discutir o tema.

O caso das eleições de 2012 no município de José de Freitas, no Estado de Piauí, foi pioneiro neste tema. As coligações que foram criadas para formarem as chapas de vereadores do município fraudaram as candidaturas femininas para garantir a reserva mínima legal do gênero, o que gerou discussão que foi levada, por meio de recursos, ao Tribunal Superior Eleitoral ${ }^{15}$.

Foram ajuizadas 2 ações sobre o mesmo tema: uma Ação de Investigação Judicial Eleitoral (AIJE) e uma Ação de Impugnação de Mandato Eletivo (AIME). As duas ações foram indeferidas com fundamento de que a via eleita é inadequada para apurar fraude à cota de gênero nas eleições. $\mathrm{O}$ assunto, ao chegar ao Tribunal Superior Eleitoral, gerou grande discussão e abriu precedente para o uso dessas ações com a finalidade apresentada.

A AIJE versa sobre a Coligação Por Um Novo Tempo, chapa de vereadores, que concorreu para as eleições de 2012. Dentre os pedidos da ação, está a anulação da chapa de vereadores da coligação por ter sido registrada mediante fraude e ter desrespeitado a reserva legal de gênero. Explica-se que houve vício de consentimento de três filiadas que desconheciam

\footnotetext{
${ }^{15}$ BRASIL. Tribunal Superior Eleitoral. Recurso Especial Eleitoral no 243-42.2012.6.18.0024. Relator: Henrique Neves da Silva. Diário da Justiça Eletrônico. Brasília, 10 out. 2016.
} 
o lançamento de suas respectivas candidaturas e renunciaram no momento que descobriram a fraude. Além disso, houve registro de candidatura de filiada analfabeta e, por fim, as duas últimas candidatas restantes da coligação tiveram votação pífia (uma delas não teve votos e a outra teve apenas um). Ao longo do processo, o juízo a quo assentou pela inadequação da via eleita.

Em sede de Recurso Especial Eleitoral, o relator, Sr. Ministro Henrique Neves da Silva, entendeu que, de fato, a Ação de Investigação Judicial Eleitoral não é a via correta para alegar a existência de fraude eleitoral no preenchimento das vagas de acordo com o percentual mínimo e máximo (previsto no $\int 3^{\circ}$ do art. 10 da Lei $n^{\circ}$ 9.504/97), uma vez que a matéria poderia ser apurada ou no momento da apreciação do Demonstrativo de Regularidade de Atos Partidários (DRAP) ou por via de Ação de Impugnação de Mandato Eletivo. Ou seja, o relator do presente caso em análise concordou, preliminarmente, com o juízo a quo acerca do uso da inadequação de AIJE para apurar fraude.

Porém, a discussão do acórdão passou a evoluir, uma vez que o relator entendeu também que

a interpretação das regras previstas no art. 22 da Lei Complementar $\mathrm{n}^{\circ}$ 64/90 não pode ser centrada apenas em caráter meramente formal, que privilegia o direito processual (acessório), em detrimento da análise de eventual violação de direito material (principal), cuja proteção constitui dever do Estado ${ }^{16}$.

Ele entende que as regras previstas na Lei das Inelegibilidades e no ordenamento jurídico eleitoral infraconstitucional devem partir da concepção traçada pela Constituição Federal, em seu artigo 14, que dispõe sobre a preservação da normalidade e da legitimidade dos pleitos e sobre a possibilidade de cassação dos mandatos em razão de abuso, fraude ou corrupção.

Deste modo, haveria um vácuo na prestação jurisdicional no período compreendido entre a apreciação do DRAP (que antecede o exame dos pedidos de candidatura) e a propositura da ação de impugnação de mandato eletivo (que, por óbvio, tem como pressuposto fático a existência de mandato a ser impugnado). Ou seja, de acordo com o relator,

\footnotetext{
${ }^{16}$ BRASIL. Tribunal Superior Eleitoral. Recurso EspecialEleitoral no 243-42.2012.6.18.0024. Relator: Henrique Neves da Silva. Diário da Justiça Eletrônico. Brasília, 10 out. 2016.
} 
[...] a alegação de fraude superveniente, em razão da inexistência de candidaturas reais capazes de efetivamente atender aos percentuais mínimos de gênero previsto na legislação, ficaria relegada e somente poderia ser examinada se e quando fosse obtido o mandato eletivo, com o ajuizamento da respectiva AIME, ao passo que não haveria espaço para a apuração da ilicitude nas situações em que os autores do ardil ou as pessoas beneficiadas não obtivessem o mandato ${ }^{17}$.

Por fim, o relator reconhece o cabimento de Ação de Investigação Judicial Eleitoral para fins de verificar se os partidos efetivamente respeitam as leis eleitorais no ordenamento jurídico em relação às cotas de gênero, conforme sábia colocação:

Em palavras diretas: é possível verificar, por meio de ação de investigação judicial eleitoral, se o partido político efetivamente respeita a normalidade das eleições prevista no ordenamento jurídico - tanto no momento do registro como no curso das campanhas eleitorais, no que tange à efetiva observância da regra prevista no art. $10, \mathbb{\int} 3^{\circ}$ da Lei das Eleições - ou se há o lançamento de candidatas apenas para que se obtenha, em fraude à lei, o preenchimento do número mínimo de vagas previsto para cada gênero, sem o efetivo desenvolvimento das candidaturas.

Por certo não se trata de impor ou examinar a completa isonomia entre os candidatos. Os partidos podem definir os candidatos que mereçam maior apoio ou destaque, por exemplo, na propaganda eleitoral. O que deve ser verificado é se as candidaturas, ainda que com poucos recursos, efetivamente existem ${ }^{18}$.

O acórdão teve, ainda, pedido de vista da ministra Luciana Lóssio e do ministro Herman Benjamin, que, apesar de concordarem com o relator, teceram novos argumentos acerca do tema.

A ministra fez uma breve análise sobre a participação feminina na política, sob a ótica do ordenamento jurídico. Trouxe para a discussão a mudança na lei eleitoral para que a cota de gênero seja respeitada, e o entendimento do Tribunal Superior Eleitoral de que, se o percentual mínimo de candidaturas femininas (qual seja, 30\%) não for alcançado, o partido ou

${ }^{17}$ BRASIL. Tribunal Superior Eleitoral. Recurso Especial Eleitoral nํㅡㄹ 243-42.2012.6.18.0024. Relator: Henrique Neves da Silva. Diário da Justiça Eletrônico. Brasília, 10 out. 2016. ${ }^{18}$ Ibid. 
coligação deve reduzir o número de candidaturas masculinas para obter a adequação necessária que a lei eleitoral exige, sob pena de indeferimento do demonstrativo de regularidade dos atos partidários (DRAP).

Ela entendeu que, diante da gravidade dos fatos, a propositura de Ação de Investigação Eleitoral era cabível para a apuração de fraude,

com fundamento em eventual abuso de poder político por parte do partido/coligação e de seus representantes, que supostamente forjaram candidaturas femininas, e até mesmo com fundamento na configuração de fraude à lei, em primazia do princípio da inafastabilidade de jurisdição, como pontuou o eminente relator, a fim de se garantir a lisura do pleito ${ }^{19}$.

Já o ministro construiu seus argumentos com base em dados sobre a participação da mulher na política brasileira e fez críticas quanto à fraude à cota de gênero nas eleições.

O ministro Herman Benjamin se mostrou enfático no tema ao afirmar que:

a previsão de cota de gênero em nosso ordenamento jurídico possui extrema relevância na medida em que visa proporcionar às mulheres isonomia plena. Por isso, deve ser interpretada de modo restrito, não se permitindo, sob qualquer justificativa, que essa importantíssima regra constitua objeto de burla ou mitigação ${ }^{20}$.

Em sede de Ação de Investigação Judicial Eleitoral, o Tribunal Superior Eleitoral decidiu, portanto, que essa ação era via adequada para apurar casos de fraude à cota de gênero instituída pela legislação eleitoral.

Já a AIME, assim como na AIJE, também tratou sobre a apresentação de requerimentos de registro de candidatura femininas de forma fraudulenta, baseado em vício de consentimento de três filiadas que não sabiam do lançamento das suas candidaturas e que renunciaram após tomar ciência do fato, em registro de candidatura de filiada analfabeta e em duas candidatas que tiveram votação inexpressiva. Ao longo do processo, o juízo

\footnotetext{
${ }^{19}$ BRASIL. Tribunal Superior Eleitoral. Recurso Especial Eleitoral no 243-42.2012.6.18.0024. Relator: Henrique Neves da Silva. Diário da Justiça Eletrônico. Brasília, 10 out. 2016. ${ }^{20}$ Ibid.
} 
a quo assentou pela inadequação da via eleita, por entender que a questão não se enquadrava como fraude para fins de ajuizamento da ação.

Em decisão de Recurso Especial Eleitoral, o relator, Sr. Ministro Henrique Neves da Silva, também entendeu que a Ação de Impugnação de Mandato Eletivo não é a via correta para alegar a existência de fraude eleitoral no preenchimento das vagas de acordo com o percentual mínimo e máximo (previsto no $\int 3^{\circ}$ do art. 10 da Lei n 9.504/97). O relator concordou, inicialmente, com o juízo a quo acerca do uso da inadequação de AIME para apurar fraude.

Porém, o relator reconheceu que este caso merecia outra solução, afirmando que o termo fraude, estampado no art. 14, \10, da Constituição Federal, que encerra conceito aberto ao englobar todas as situações de fraude - inclusive a de fraude à lei - que possam afetar a normalidade das eleições e a legitimidade do mandato obtido ${ }^{21}$.

Ao desenvolver seu argumento, o relator afirmou que o termo fraude deve ser interpretado extensivamente, de forma a abarcar o cabimento da AIME e que também deve levar em consideração as demais regras e princípios dispostos na Constituição Federal. Ele retornou aos fatos que deram origem à ação em discussão e mostrou, didaticamente, que as posturas adotadas ensejavam fraude e que assim deviam ser julgadas.

No acórdão, em fase de esclarecimentos, bem apontou a ministra Luciana Lóssio:

[...] é uma prática reiterada que foi adotada nas eleições do Estado do Piauí. Se não admitirmos que a Justiça Eleitoral tenha conhecimento na Ação de Impugnação de Mandato Eletivo, essa fraude não chegará à apreciação da Justiça, porque, na impugnação de Demonstrativo de Regularidade de Atos Partidários (DRAP), tal fraude ainda não é do conhecimento de ninguém, ou seja, esse tipo ardil ficará impune $e^{22}$.

Em sede de AIME, portanto, o Tribunal Superior Eleitoral admitiu o uso desse tipo de ação para apurar os casos de fraude à cota de gênero nas eleições, instituída pela Lei das Eleições.

${ }^{21}$ BRASIL. Tribunal Superior Eleitoral. Recurso Especial Eleitoral nํำ1-49.2013.6.18.0024. Relator: Henrique Neves da Silva. Diário da Justiça Eletrônico. Brasília, 21 out. 2015.

${ }^{22}$ Ibid. 
Cabe reiterar que as decisões basearam-se apenas nas alegações de fraude na medida cabível para a apuração das mesmas. O Tribunal Superior Eleitoral não analisou o mérito das ações e nem as decisões a serem tomadas. Após o julgamento das ações como via eleita corretamente, foi determinada a remessa para o Tribunal de origem processar e julgar o mérito da lide.

Após o estudo desse caso, é possível compreender por que a falta de atenção adequada à prática de fraude às cotas de gênero por meio de "candidatas laranjas" nas eleições brasileiras. Considerando não encontrar meios adequados para denunciar e punir essas práticas, a sociedade encontrava-se sem amparo judicial para resolver os atos ilícitos praticados pelos partidos políticos e coligações.

O caso do município José de Freitas, no Estado do Piauí, abriu precedente para se discutir abertamente a utilização de candidaturas fraudulentas nas eleições para cumprir o que dispõe o ordenamento jurídico eleitoral. Atualmente, é possível, portanto, encontrar instrumentos processuais aptos a discutir e averiguar atos ilícitos, e caminhar, dessa forma, para alcançar a igualdade de gênero na política.

\section{O julgamento das fraudes no TSE}

Superada a questão do gargalo processual, a discussão acerca das candidatas laranjas toma um novo rumo. Agora que é possível judicializar, processar e julgar a fraude no processo eleitoral envolvendo a cota de gênero, um novo obstáculo deve ser amplamente discutido para ser superado.

O que se discute agora é o teor das condenações, caso seja comprovada a fraude no processo eleitoral com candidaturas fictícias: Qual punição à prática é justa o suficiente para inibir novos casos nas eleições brasileiras? Qual impacto ela pode trazer para a política e para a sociedade?

O Estado do Piauí, mais uma vez, abre precedente nos julgamentos de candidatas laranjas no Tribunal Superior Eleitoral. Dessa vez, a pauta de discussão é focada no julgamento do mérito das ações que versam sobre a cota de gênero nas eleições.

A Ação de Investigação Judicial Eleitoral (AIJE) tratou sobre as eleições municipais de 2016, na cidade de Valença do Piauí/PI. As coligações Compromisso com Valença I e Compromisso com Valença II foram condenadas por apresentarem 5 candidaturas femininas laranjas, pois estas 
tiveram votação pífia, não tiveram gastos nas respectivas prestações de conta e não praticaram campanha eleitoral. A punição, em primeira instância - que foi mantida no Tribunal Regional Eleitoral de Piauí - cassou todas as 29 candidaturas lançadas (sendo 6 candidatos eleitos) pelas coligações e tornou os candidatos inelegíveis ${ }^{23}$.

Em sede de recurso ao TSE, o caso foi a plenário e o relator, ministro Jorge Mussi, votou no sentido de manter a decisão de cassação das 2 coligações que cometeram a fraude, pois entende que, sem as candidaturas fictícias, as chapas não teriam alcançado a exigência normativa da cota de gênero, logo, não participariam das eleições municipais daquele ano. Argumenta que, deste modo, todos os candidatos se beneficiaram da fraude cometida ${ }^{24}$.

No que tange a inelegibilidade, aduz que não deve ser aplicada na mesma extensão que a cassação, uma vez que, de acordo com a jurisprudência do Tribunal, tal sanção tem caráter personalíssimo e deve ser aplicada apenas àqueles que cometeram, participaram ou anuíram para o ato ilícito e não apenas quem se beneficiou. Para tanto, considera que apenas 2 candidatos devem ser considerados inelegíveis, pois estes tiveram respectivamente mãe e esposa registradas como candidatas, ainda que estas não tenham praticado atos de campanha - pelo contrário, pediam votos para seu filho e marido, respectivamente, em redes sociais - o que torna possível o reconhecimento de participação e/ou anuência e envolvimento na fraude eleitoral.

O julgamento, porém, foi suspenso, uma vez que o ministro Edson Fachin fez pedido de vista para que pudesse analisar detalhadamente as questões que restam sobre a cassação de todos os candidatos ${ }^{25}$.

${ }^{23}$ TSE analisa benefício a candidatos do PI por candidaturas femininas fantasmas. Tribunal Superior Eleitoral, Brasília, DF, 14 mar. 2019. Disponível em: <http://www.tse.jus. br/imprensa/noticias-tse/2019/Marco/tse-decidira-sobre-inelegibilidade-de-candidatos-que-teriam-se-beneficiado-de-candidaturas-femininas-fantasmas-no-piaui>. Acesso em: 5 maio 2019.

${ }^{24}$ TSE analisa benefício a candidatos do PI por candidaturas femininas fantasmas. Tribunal Superior Eleitoral, Brasília, DF, 14 mar. 2019. Disponível em: <http://www.tse.jus. br/imprensa/noticias-tse/2019/Marco/tse-decidira-sobre-inelegibilidade-de-candidatos-que-teriam-se-beneficiado-de-candidaturas-femininas-fantasmas-no-piaui>. Acesso em: 5 maio 2019.

${ }^{25}$ Até a conclusão do presente artigo, o julgamento do Recurso Especial Eleitoral não havia sido retomado. 
A discussão de que o julgamento desse caso diz respeito aos impactos que a condenação pode trazer para a política, o processo eleitoral e a sociedade. $\mathrm{O}$ assunto deve ser analisado com cautela, uma vez que pode impactar diretamente na vontade do povo e no resultado das urnas. Deve ser observado o caso como um todo, mas também todos os envolvidos individualmente. A decisão pode atingir candidatos que desconheciam a fraude e também as candidatas mulheres, que podem ser consideradas como vítimas do sistema empregado.

O vice-procurador-geral eleitoral, Humberto Jacques de Medeiros, entende que as pessoas e os partidos que utilizam a fraude no processo eleitoral por meio de candidaturas fictícias femininas, estão fraudando princípios constitucionais e impedem o acesso da mulher à política. Argumenta, ainda, que

a sanção devida, a quem não guarda nenhuma lealdade à existência de uma democracia com alternância no poder e na igualdade de oportunidade a todos, não pode ficar aquém da inelegibilidade por fraude e abuso de poder exercidos na sua mais intensa densidade. ${ }^{26}$

Para Carolina Clève, advogada eleitoral, cassar todos os candidatos eleitos pelo partido/coligação é uma punição muito severa, pois considera que tal condenação invalidaria os votos de todo o eleitorado, interferindo na vontade popular. Ressalta que a punição pode ter efeito contrário, uma vez que também será possível cassar mandatos de mulheres democraticamente eleitas, ferindo, dessa maneira, a participação feminina na política. Por fim, Clève entende que o julgamento do TSE formará um precedente para demonstrar que a lei deve ser respeitada ${ }^{27}$.

O advogado Wallyson Soares dos Anjos, representante da coligação que apresentou a denúncia do caso à Justiça Eleitoral, entende que as candidaturas femininas que servem apenas para garantir as candidaturas

${ }^{26}$ TSE analisa benefício a candidatos do PI por candidaturas femininas fantasmas. Tribunal Superior Eleitoral, Brasília, DF, 14 mar. 2019. Disponível em: < http://www.tse.jus.br/imprensa/ noticias-tse/2019/Marco/tse-decidira-sobre-inelegibilidade-de-candidatos-que-teriam-se-beneficiado-de-candidaturas-femininas-fantasmas-no-piaui>. Acesso em: 5 maio 2019.

${ }^{27}$ KADANUS, Kelli. Candidatas laranjas: o caso que pode gerar efeito cascata de cassações por todo Brasil. Gazeta do Povo, 25 mar. 2019. Disponível em: < https://www.gazetadopovo.com.br/politica/republica/candidatas-laranjas-o-caso-que-pode-gerar-efeito-cascata-de-cassacoes-por-todo-brasil-cxok3i9mys71e4luqfj3myelf/>. Acesso em: 6 maio 2019. 
masculina influenciam toda a chapa e a própria eleição. Por esse motivo, ele defende que o prefeito e o vice-prefeito eleitos naquele pleito também devem ter seus mandatos cassados ${ }^{28}$.

Já para o advogado que representa as coligações que foram denunciadas, Norberto Campelo, esse julgamento exige do TSE cautela para avaliar as consequências que a decisão pode trazer não apenas em âmbito local, mas também na política nacional. Ele entende que, caso a decisão do TRE-PI seja mantida, cada candidato deverá ter a postura de fiscal para com os demais candidatos, o que pode facilmente sair de controle. Por esse motivo, acredita que a cassação de todos os candidatos, eleitos ou não, é a maior preocupação que os julgadores devem $\operatorname{ter}^{29}$.

O professor de direito eleitoral, Diogo Rais, pondera os diferentes aspectos do julgamento pelo TSE e afirma que é um debate com pontos sensíveis. Entende que, se mantida a decisão do TRE-PI, a punição pode afetar candidatos que desconheciam a fraude, cassar mulheres democraticamente eleitas e mudar o resultado daquela eleição. Mas também diz que uma decisão moderada pode fazer com que o ato ilícito continue sendo cometido por partidos e coligações ${ }^{30}$.

O debate acerca do tema é amplo e alcança diferentes esferas. No entanto, a conclusão é incerta pois a matéria é, de fato, trabalhosa e sensível em diversos pontos. O debate não deve acabar apenas na questão do que é justo ou injusto para o caso. Cabe ao TSE julgar a lide da melhor forma que entender.

Cumpre ressaltar que, apesar de ser uma matéria de cunho difícil e de traços sensíveis, o julgamento não pode ser adiado a ponto de perder a matéria julgada com o fim dos mandatos eletivos que estão em curso. O debate, portanto, também levanta a questão de que a decisão pode ser injusta, mas a sua demora a ser concretizada também será injusta.

${ }^{28}$ QUEIROGA, Louise. Candidaturas 'laranjas' de mulheres ligam o alerta da Justiça Eleitoral. O Globo, 9 jul. 2018. Disponível em: < https://oglobo.globo.com/brasil/candidaturas-laranjas-de-mulheres-ligam-alerta-da-justica-eleitoral-22867031>. Acesso em: 6 maio 2019. ${ }^{29}$ Ibid.

${ }^{30}$ VENTURINI, Lilian. Como esta ação pode definir a punição de laranjas eleitorais. Nexo Jornal, 17 mar. 2019. Disponível em: <https://www.nexojornal.com.br/expresso/2019/03/17/Como-esta-a \%C3\%A7\%C3\%A3o-pode-definir-a-puni $\%$ C3\%A7\%C3\%A3o-de-laranjas-eleitorais>. Acesso em: 6 maio 2019. 
O julgamento do TSE, de certo, abrirá precedente e uniformizará a jurisprudência na Justiça Eleitoral, mas a cautela ainda deve permanecer presente mesmo que o caso exija urgência.

\section{Considerações finais}

O sistema normativo eleitoral brasileiro buscou de forma concisa alcançar a igualdade de gênero na política através, dentre outras, da cota de gênero, porém o esforço do poder público infelizmente ainda não obteve tanta eficácia. A participação feminina na política atualmente é baixa e não representa a realidade brasileira, uma vez que, conforme mencionado anteriormente, de acordo com o TSE, o eleitorado, em 2018, era formado, em sua maioria, por mulheres.

A cota de gênero encontra-se no art. 10, \ $3^{\circ}$, da Lei das Eleições, e dispõe expressamente que deve ser reservado no mínimo 30\% das candidaturas para um dos sexos nas eleições proporcionais. Vemos aqui, o esforço do poder público em igualar a representatividade das mulheres na política não só no plano teórico, mas principalmente no plano real, porém a lei não é cumprida, tampouco fiscalizada como deveria ser.

Os partidos políticos buscaram formas de fraudar a lei e utilizaram candidaturas femininas fictícias para "maquiar" as eleições proporcionais, apenas para não diminuir o número de vagas destinadas ao público masculino. As candidatas laranjas são, portanto, um instrumento dos partidos políticos e/ou coligações para lesar as eleições e, de forma extensa, dissimular a realidade para o eleitorado.

Essa prática, porém, passou a ser discutida recentemente quando foram superados os obstáculos processuais que aqueles que denunciavam a prática ilícita encontravam, afinal não havia ações judiciais possíveis para julgar a fraude eleitoral.

O julgamento das ações de Investigação Judicial Eleitoral e Impugnação de Mandato Eletivo abriram precedente para a discussão do problema em âmbito judicial. O Tribunal Superior Eleitoral assentou pelo reconhecimento das duas ações como instrumentos processuais para a judicialização e o julgamento dos atos ilícitos praticados pelos partidos políticos e coligações. O primeiro obstáculo, portanto, foi superado.

Agora, o que está em pauta é o julgamento do mérito das lides. O caso de Valença do Piauí/PI abriu precedente para a uniformização da ju- 
risprudência na justiça eleitoral. A discussão sobre as candidaturas laranjas atingiu um novo nível ao encarar qual é a punição mais justa - ou menos injusta - para os casos.

O caso está em fase de julgamento pelo TSE e apresenta pontos sensíveis na discussão, uma vez que a punição pode alcançar candidatos que desconheciam a fraude e/ou candidatas mulheres, e pode mudar o resultado das urnas.

Porém a discussão sobre o caso não deve parar apenas na esfera do que é justo ou injusto. Deve-se discutir também sobre a morosidade da justiça eleitoral em julgar lides tão importantes.

O caso de Valença do Piauí é um exemplo a ser tomado, uma vez que a lide diz respeito às eleições municipais de 2016 e o julgamento do Recurso Especial Eleitoral no TSE ainda não foi concluído, ou seja, a eficácia da decisão sobre o tema pode ser prejudicada com a perda do objeto da ação, uma vez que os mandatos eletivos terão seu término em 2020.

A Justiça Eleitoral, como é de conhecimento geral, tem como característica principal a rapidez e a urgência com que os casos devem ser tratados. Nas primeiras instâncias, os prazos processuais são curtos, com a finalidade de acelerar o julgamento das lides para não sofrer com a morosidade posteriormente. O caso de Valença do Piauí exige a mesma agilidade uma vez que a ação está em curso há 3 anos.

Em casos como esse, que necessitam de segurança jurídica e maior cautela nas decisões, são compreensíveis os motivos para a demora e as extensas discussões que são abarcadas com os temas, porém é dever lembrar que, de a decisão pode se tornar injusta, sua falta também pode configurar igual injustiça.

A expressão "a justiça tarda, mas não falha" não pode ser considerada de forma literal, pois, como todos os operadores de direito bem sabem, a justiça que tarda, certamente falhará em algum ponto. E casos em que são exigidas cautela e urgência devem sempre prezar pela segurança jurídica, visando à eficácia que alcançarão.

O presente trabalho buscou, portanto, entender os entraves jurídicos no julgamento das fraudes cometidas no processo eleitoral através de candidatas laranjas, e explicar de forma concisa quais foram as maneiras de superá-los, e quais os debates atuais sobre o tema no âmbito judicial. 


\section{Referências}

BERTHA Lutz. Senado Notícias, Brasília, DF, 2015. Disponível em: $<$ https://www12.senado.leg.br/noticias/entenda-o-assunto/bertha-lutz> Acesso em: 9 maio 2019.

BRASIL. Câmara dos Deputados. Comissão de Direitos Humanos e Minorias. Declaração de Pequim Adotada pela Quarta Conferência Mundial sobre as Mulheres: Ação para Igualdade, Desenvolvimento e Paz. IV Conferência Mundial Sobre as Mulheres, Pequim, 15 set. 1995. Disponível em: $<$ https://www2.camara.leg.br/atividade-legislativa/comissoes/comissoes-permanentes/cdhm/comite-brasileiro-de-direitos-humanos-e-politica-externa/DecPequimquartconfmulh.html> Acesso em: 7 maio 2019.

BRASIL. Câmara dos Deputados. Diploma Mulher-Cidadã Carlota Pereira de Queirós. Comissão de Defesa dos Direitos da Mulher. Brasília, DF, 2018. Disponível em: < https://www2.camara.leg.br/atividade-legislativa/ comissoes/comissoes-permanentes/comissao-de-defesa-dos-direitos-da-mulher-cmulher/seminarios-e-outros-eventos/diploma-mulher-cidada-carlota-pereira-de-queiros/edicao-2018-diploma-mulher-cidada-carlota-pereira-de-queiros/resumo-alzira-soriano> Acesso em: 9 maio 2019.

BRASIL. Decreto no 21.076, de 24 de fevereiro de 1932. Decreta o Código Eleitoral. Disponível em: < https://www2.camara.leg.br/legin/fed/ decret/1930-1939/decreto-21076-24-fevereiro-1932-507583-publicacaooriginal-1-pe.html> Acesso em: 1 maio 2019.

BRASIL. Lei no 12.034, de 30 de setembro de 2009. Altera as Leis no ${ }^{\circ}$.096, de 19 de setembro de 1995 - Lei dos Partidos Políticos, 9.504, de 30 de setembro de 1997, que estabelece normas para as eleições, e 4.737, de 15 de julho de 1965 - Código Eleitoral. Disponível em: <http:/ /www.planalto.gov. br/ccivil_03/_Ato2007-2010/2009/Lei/L12034.htm> Acesso em: 8 maio 2019 .

BRASIL. Lei no 9.100, de 29 de setembro de 1995. Estabelece normas para a realização das eleições municipais de 3 de outubro de 1996, e dá outras providências. Disponível em: <http://www.planalto.gov.br/ccivil_03/leis/ L9100.htm> Acesso em: 8 maio 2019.

BRASIL.. Lei no 9.504, de 30 de setembro de 1997. Estabelece normas para as eleições. Disponível em: < http://www.planalto.gov.br/ccivil_03/leis/ 19504.htm> Acesso em: 1 maio 2019. 
BRASIL. Lei $\mathbf{n}^{\circ} \mathbf{9 . 5 0 4}$, de 30 de setembro de 1997. Estabelece normas para as eleições. Disponível em: <http://www.planalto.gov.br/ccivil_03/leis/ 19504.htm> Acesso em: 8 maio 2019.

BRASIL. Senado Federal. Procuradoria Especial da Mulher. Mulheres na Política: pesquisa realizada pelo DataSenado. Senado Federal, Brasília, DF, 2014. Disponível em: < https://www12.senado.leg.br/institucional/procuradoria/proc-publicacoes/cartilha-mulheres-na-politica> Acesso em: 9 maio 2019.

BRASIL. Tribunal Superior Eleitoral. Recurso Especial Eleitoral no 243 42.2012.6.18.0024. Relator: Henrique Neves da Silva. Diário da Justiça Eletrônico. Brasília, 10 out. 2016.

BRASIL. Tribunal Superior Eleitoral. Recurso Especial Eleitoral $\mathrm{n}^{\circ}$ 1-49.2013.6.18.0024. Relator: Henrique Neves da Silva. Diário da Justiça Eletrônico. Brasília, 21 out. 2015.

DELGADO, Malu. Não há mais espaço para fraudes com candidatas laranjas, diz ex-ministra. Valor Econômico, 25 fev. 2019. Disponível em: <https:// www.valor.com.br/politica/6135453/nao-ha-mais-espaco-para-fraude-com-candidatas-laranjas-diz-ex-ministra> Acesso em: 6 maio 2019.

EQUIDADE de Gênero na Política 2016. Senado Notícias, Brasília, DF, 2016. Disponível em: < https://www12.senado.leg.br/institucional/procuradoria/proc-publicacoes/pesquisa-equidade-de-genero-na-politica-2016> Acesso em: 9 maio 2019.

ESTATÍSTICAS Eleitorais. 2016 e 2018 - Candidatura e Eleitorado. Tribunal Superior Eleitoral, Brasília, DF, s.d. Disponível em: <http://www.tse. jus.br/eleicoes/estatisticas/estatisticas-eleitorais> Acesso em: 8 maio 2019.

FALCÃO, Márcio. Ministros do TSE divergem sobre cassação de coligação por candidatas laranjas. Jota Info, 14 mar. 2019. Disponível em: <https:/ / www.jota.info/paywall?redirect_to $=/ /$ www.jota.info/justica $/$ ministros-do-tse-divergem-sobre-cassacao-de-coligacao-por-candidatas-laranjas-14032019> Acesso em: 5 maio 2019

JUVÊNCIO, José Sérgio Martins. A relação entre candidaturas "laranjas" e a lei de cotas por gênero. In: Encontro Internacional Participação, Democracia e Políticas Públicas: aproximando agendas e agentes, 1.2013, Araraquara. Encontro Araraquara: UNESP, 2013. 
KADANUS, Kelli. Candidatas laranjas: o caso que pode gerar efeito cascata de cassações por todo Brasil. Gazeta do Povo, 25 mar. 2019. Disponível em: <https://www.gazetadopovo.com.br/politica/republica/candidatas-laranjas-o-caso-que-pode-gerar-efeito-cascata-de-cassacoes-por-todo-brasil-cxok3i9mys71e4luqfj3myelf/> Acesso em: 6 maio 2019.

MACHADO, Raquel Cavalcanti Ramos. Guia prático: A participação da mulher brasileira na política. Fortaleza: Observatório Eleitoral do Ceará, 2019.

MELO, Hildete Pereira de. A política de cotas para as mulheres no Brasil: importância e desafios para avançar. Gênero e Número, 13 set. 2018. Disponível em <http://www.generonumero.media/a-politica-de-cotas-para-as-mulheres-no-brasil-importancia-e-desafios-para-avancar/> Acesso em 4 maio 2019.

PASSARELLI, Eliana. Cota de gênero não contribui para aumentar a representação feminina. Folha de S. Paulo, São Paulo,16 jul. 2018. Disponível em: <https://www1.folha.uol.com.br/poder/2018/07/cota-de-genero-nao-contribui-para-aumentar-a-representacao-feminina.shtml> Acesso em: 4 maio 2019.

PROFESSORA Celina Guimarães Vianna, primeira eleitora do Brasil. Tribunal Superior Eleitoral, Brasília, DF, s.d. Disponível em: < http://www.tse. jus.br/imagens/fotos/professora-celina-guimaraes-vianna-primeira-eleitora-do-brasil> Acesso em 9 maio 2019.

QUEIROGA, Louise. Candidaturas 'laranjas' de mulheres ligam o alerta da Justiça Eleitoral. O Globo, 9 jul. 2018. Disponível em: < https://oglobo. globo.com/brasil/candidaturas-laranjas-de-mulheres-ligam-alerta-da-justica-eleitoral-22867031> Acesso em: 6 maio 2019.

SENA, Yala. Julgamento de candidatas laranjas do Piauí pode abrir precedente para partidos. Folha de S. Paulo, São Paulo, 26 abr. 2019. Disponível em: <https://www1.folha.uol.com.br/poder/2019/04/julgamento-de-candidatas-laranjas-do-piaui-pode-abrir-precedente-para-os-partidos.shtml?loggedpaywall> Acesso em: 6 maio 2019.

TSE analisa benefício a candidatos do PI por candidaturas femininas fantasmas. Tribunal Superior Eleitoral, Brasília, DF, 14 mar. 2019. Disponível em: <http://www.tse.jus.br/imprensa/noticias-tse/2019/Marco/tse-decidira-sobre-inelegibilidade-de-candidatos-que-teriam-se-beneficiado-de-candidaturas-femininas-fantasmas-no-piaui> Acesso em: 5 maio 2019. 
VENTURINI, Lilian. Como esta ação pode definir a punição de laranjas eleitorais. Nexo Jornal, 17 mar. 2019. Disponível em: < https://www.nexojornal. com.br/expresso/2019/03/17/Como-esta-a \%CC3\%A7\%C3\%A3o-pode-definir-a-puni $\%$ C3\%A7\%C3\%A3o-de-laranjas-eleitorais> Acesso em: 6 maio 2019.

Camila Teixeira do Nascimento - Bacharel em Direito pela Universidade Presbiteriana Mackenzie. Integrante do Grupo Mackeleições.

Diogo Rais Rodrigues Moreira - Doutor e Mestre em Direito do Estado pela PUC-SP. Coordenador dos livros: Fake News, a conexão entre a desinformação e o direito; Direito Eleitoral Digital (ambos da Revista dos Tribunais - Thomson Reuters, 2018). Coordenador do grupo MackEleições e Professor de Direito Eleitoral da Universidade Presbiteriana Mackenzie. 
